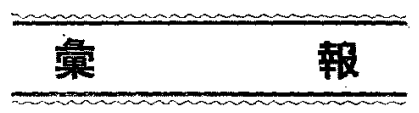

\title{
牛及豚の生體量と枝肉量との關係 所謂枝肉步留りに就て
}

朝觯黑木昌章

\section{1. 緒言}

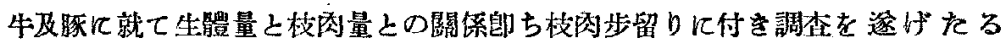

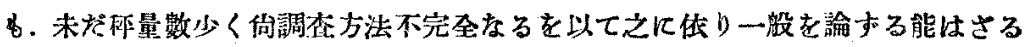
も揤か沉ても斯學の參考之ならば幸莣なり。

\section{2. 科量 方法}

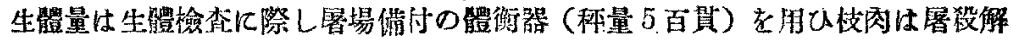
體後直ちに「露雬」を以て科量したり。

\section{3. 牛 (朝鮮在來理)}

(1) 科量頭數 (1) 性别頭数

辈2 950 頭

\begin{tabular}{|c|c|c|c|c|c|c|c|c|c|c|c|c|c|c|}
\hline 别 年橎别 & $3 \quad \frac{1}{1}$ & 歳 & 4 & & 5 & 歲 & 6 & 歳 & 7 & 歲 & 8 & 藏 & & 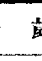 \\
\hline 特 & & - & & - & & - & & 18 & & 54 & & 18 & & \\
\hline 性: & & 3 & & 3 & & 15 & & 138 & & 75 & & 1 & & \\
\hline
\end{tabular}

（2）性别技闪步留萃(1 頭平均)

\begin{tabular}{|c|c|c|c|c|c|c|c|c|c|c|}
\hline 性 & 别 & 生 & 骿 & 量 & 枝 & 闪 & 量 & 齿 & 留 & 愁 \\
\hline & 牝 & & & 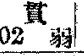 & & \multicolumn{2}{|c|}{$\begin{array}{c}\text { 贯 } 8 \text { 多 } \\
50.687 \text { 弱 }\end{array}$} & \multicolumn{3}{|r|}{5 割弱 } \\
\hline & 壮. & & & 17 弱 & & \multicolumn{2}{|c|}{55.133 诸 } & \multicolumn{3}{|c|}{4 割7分强 } \\
\hline
\end{tabular}


（3）年褕别枝刚步留率

(1) 此 (1 頭平均)

\begin{tabular}{|c|c|c|c|c|c|c|c|c|c|c|}
\hline 年 閝 & 别 & 生 & 體 & 量 & 枝 & 肉 & 量 & 步 & 留 & 錅 \\
\hline 6 & 藏。 & & & & & & 49.130 & & & 割 1 競 \\
\hline 7 & 歳 & & & 10 & & & 50.700 & & & 5.1 坊 \\
\hline 8 & 䖪 & & & 11 & & & 52.200 & & & 4.7 犽 \\
\hline
\end{tabular}

(口) 怔 ( 1 頍本均)

\begin{tabular}{|c|c|c|c|c|c|c|c|c|c|}
\hline 纱: 夦 & & 生 & 體 & 量 & 枝 & 肉 & 量 & 歩 & 留，育 \\
\hline 3 & 歳 & & & $\begin{array}{r}84 \\
84 \\
\end{array}$ & & & $\begin{array}{l}4 \\
37.400\end{array}$ & & $4^{4} 4^{* \frac{4}{5}}$ \\
\hline 4 & 歳 & & & 90 & & & 42.600 & & 4.7 \\
\hline 5 & 歳 & & & 105 & & & 49.480 & & 4. 7 强 \\
\hline 6 & 藏 & & & 113 & & & 50.228 & & $4.4^{\prime \prime}$ \\
\hline 7 & 藏 & & & 126 & & & 54.784 & & $4.3^{\prime \prime}$ \\
\hline 8 & 藏 & & & 138 & & & 62.675 & & $4 \quad 5^{\prime \prime}$ \\
\hline $9:$ & 藏 & & & 119 & & & 55.750 & & 4.7 㡬 \\
\hline 10 & 歲 & & & 107 & & & 46.600 & & $4: 4$ \\
\hline
\end{tabular}

（4）:步留杽别頭數

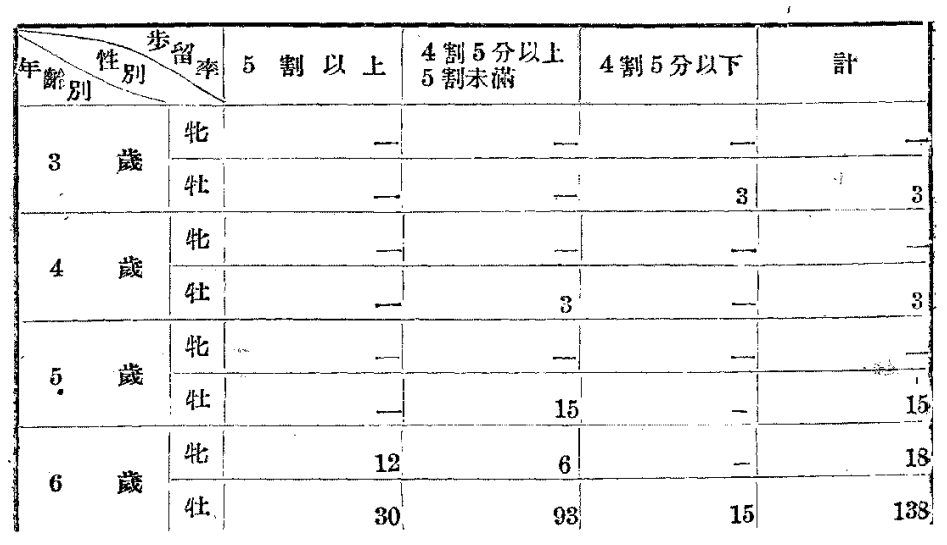




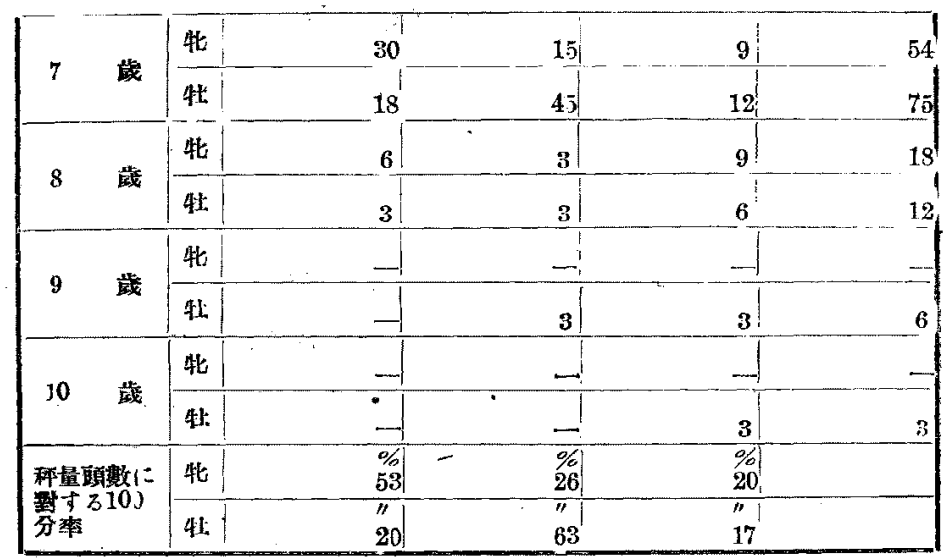

4. 睆 (雓ータシャー)

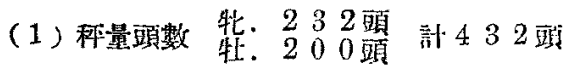

(2) 性别步留率 (1 頭4均)

\begin{tabular}{|c|c|c|c|c|c|c|c|c|c|c|}
\hline tE: & 别 & 生 & 體 & 量 & 㪔 & 闪 & 量 & 步 & 留 & 零 \\
\hline & 比 & & & 14 & & \multicolumn{3}{|c|}{$\begin{array}{r}\text { 多賁 } \\
9.633\end{array}$} & \multicolumn{2}{|c|}{6 割9 分梠 } \\
\hline & 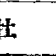 & & & $14^{\prime \prime}$ & & & 9.91 & & \multicolumn{2}{|c|}{7 割 1 分 } \\
\hline
\end{tabular}

(3) 步留率湖嘼數

\begin{tabular}{|c|c|c|c|c|c|c|c|}
\hline 性别 秒留管 & 6 & 割 & 6 割 5 分 & 割 & 7 制 5 分 & 割 & $\begin{array}{l}8 \text { 蔽上 } \\
\text { 上分 }\end{array}$ \\
\hline 特 & & $2 \stackrel{\text { 頍| }}{2}$ & 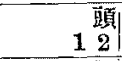 & 150 & $\begin{array}{r}91 \\
14\end{array}$ & $\begin{array}{r}\text { 頭 } \\
26\end{array}$ & $\begin{array}{l}\text { 站 } \\
8\end{array}$ \\
\hline 牞 & & $\begin{array}{lll} & 11 \\
1 & 8\end{array}$ & 4 & $122^{\prime \prime}$ & $\begin{array}{r}116 \\
\end{array}$ & $\begin{array}{r}11 \\
-30 \\
\end{array}$ & 10 \\
\hline
\end{tabular}

5. 總括

1. 牛に於て吾人は牝牛より牲牛は胃柊大なるを以て步留率にては精肉と異なり

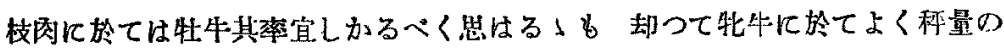

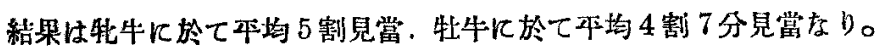

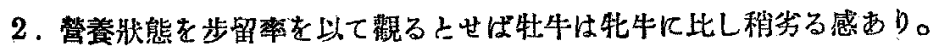

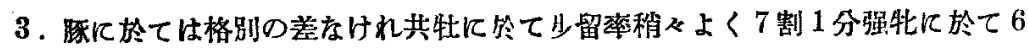


割 9 分とんふ䋊果を得をり。

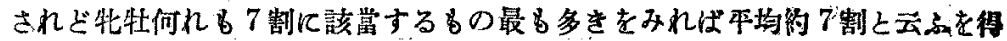
ho

\section{臺灣を視察して}

農林省技師 橫，堀 善 四 郎

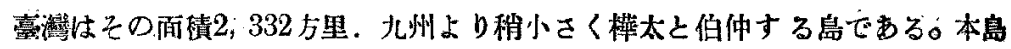

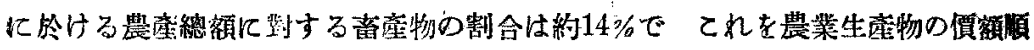

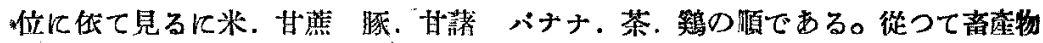

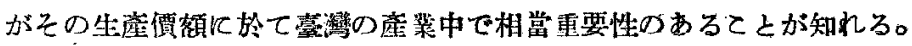

\section{臺灣の畜座}

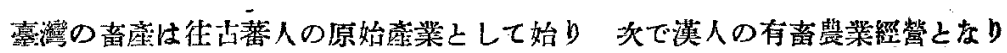

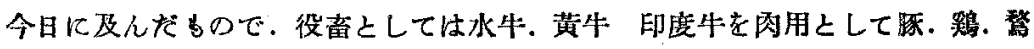
を多数に飼埕してわる。

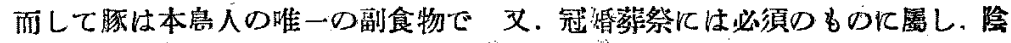

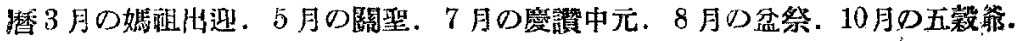

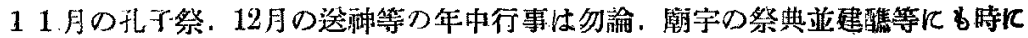

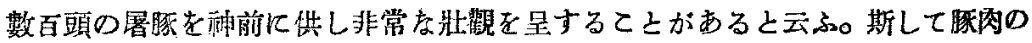

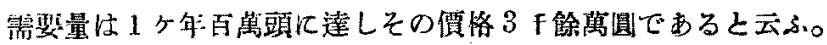

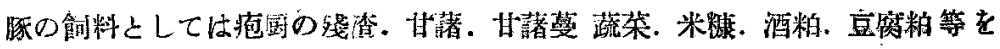

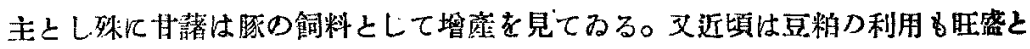
なつたと云ふ。

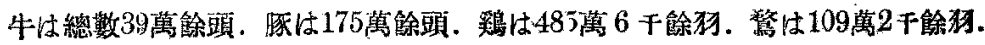

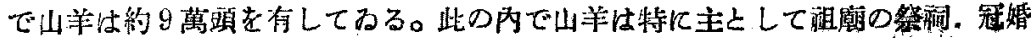

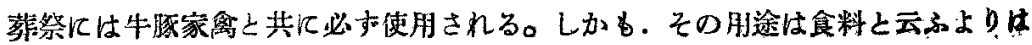

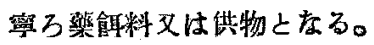

